\title{
Non-invasive markers of airway inflammation as predictors of oral steroid responsiveness in asthma
}

\author{
Stuart A Little, George W Chalmers, Kirsten J MacLeod, Charles McSharry,
} Neil C Thomson

\begin{abstract}
Background-Sputum eosinophil counts and exhaled nitric oxide (NO) levels are increased in asthma and both measurements fall in response to corticosteroids. Methods-Exhaled NO levels and sputum eosinophil counts were assessed as noninvasive markers of the response to an oral steroid in 37 patients (19 women) with stable chronic asthma (mean (SD) age 48.6 (12.2) years, asthma duration 25.9 (17.3) years, and baseline forced expiratory volume in one second $\left(F_{E V}\right) 76.3$ (21.9)\% predicted). Spirometric tests, with reversibility to a $\beta$ agonist $(2.5 \mathrm{mg}$ nebulised salbutamol), and induced sputum (using nebulised 3\% saline) were performed at recruitment and following treatment with $30 \mathrm{mg}$ prednisolone/day for 14 days.

Results-Baseline NO levels correlated with the percentage improvement in $\mathrm{FEV}_{1}$ from baseline to the post-steroid, postbronchodilator value $\left(r_{\mathrm{s}}=0.47, \mathbf{p}=0.003\right)$, with an NO level of $>10 \mathrm{ppb}$ at baseline having a positive predictive value of $83 \%$ for an improvement in $\mathbf{F E V}_{1}$ of $\geqslant 15 \%$ (sensitivity $59 \%$, specificity $90 \%$ ). Sputum eosinophilia $(\geqslant 4 \%)$ had a positive predictive value of $68 \%$ (sensitivity $54 \%$, specificity $76 \%$ ) for an increase in $\mathrm{FEV}_{1}$ of $\geqslant 15 \%$. A combination of sputum eosinophilia and increased NO levels resulted in a positive predictive value of $72 \%$ and a negative predictive value of $79 \%$ (sensitivity $76 \%$, specificity $75 \%$ ).

Conclusion-Exhaled NO levels and sputum eosinophilia may be useful in predicting the response to a trial of oral steroid in asthma.

(Thorax 2000;55:232-234)
\end{abstract}

Keywords: airway inflammation; nitric oxide; induced sputum eosinophilia; asthma; corticosteroids

Asthma is characterised by episodic reversible airway narrowing with associated bronchial hyperreactivity and the involvement of inflammation is well recognised, even in mild disease. The aim of treatment is to control symptoms and to optimise lung function, with inhaled steroids being central to the management through their effect on airway inflammation. The "gold standard" for assessing reversibility of lung function would be a trial of steroid treatment (oral prednisolone for two weeks) but this may be inappropriate in some individuals because of coexistent disease, or declined by others for various reasons. In addition, a two week steroid trial with lung function testing before and after treatment is time consuming, so a predictor of steroid response would have clinical application.

Both induced sputum eosinophil counts and exhaled NO concentrations have been used as non-invasive markers of asthmatic airway inflammation. ${ }^{1-4}$ They therefore appear appropriate for this study, the aim of which was to assess the potential of non-invasive markers of airway inflammation in predicting response to an oral steroid trial in asthma.

\section{Methods}

PATIENTS

The study was prospective, recruiting patients through the respiratory outpatient clinic and community contacts. All had a diagnosis of asthma, according to the criteria established by the American Thoracic Society, for at least five years and had had no acute exacerbation within the preceding month. All were non-smokers or, if ex-smokers, had stopped at least five years earlier and had smoked a maximum of 10 pack years. The study was approved by the West ethics committee, Western Infirmary, Glasgow. All volunteers gave informed consent.

\section{STUDY DESIGN}

The study involved two visits separated by a two week course of oral prednisolone at a dose of $30 \mathrm{mg} /$ day. Each visit involved spirometric tests (Vitalograph Ltd, Buckingham, UK), reversibility to $2.5 \mathrm{mg}$ nebulised salbutamol, measurement of exhaled nitric oxide concentrations, and induced sputum. On a third visit a histamine inhalational challenge was performed.

\section{MEASUREMENTS}

\section{Exhaled nitric oxide}

Exhaled nitric oxide measurements were performed using a Logan Research analyser (Logan Research Ltd, Rochester, Kent, UK) operating on the principle of chemilumines- 
Table 1 Value of exhaled nitric oxide, sputum eosinophilia or a combination in predicting steroid response

\begin{tabular}{|c|c|c|c|c|c|c|}
\hline & \multicolumn{2}{|c|}{ Change in FEV $V_{1}(\%)$} & \multicolumn{2}{|c|}{ Predictive value } & \multirow[b]{2}{*}{ Sensitivity } & \multirow[b]{2}{*}{ Specificity } \\
\hline & $<15 \%$ & $\geqslant 15 \%$ & Negative & Positive & & \\
\hline \multicolumn{7}{|l|}{ Nitric oxide } \\
\hline$<10 \mathrm{ppb}$ & 18 & 7 & $72 \%$ & & $59 \%$ & \\
\hline$\geqslant 10 \mathrm{ppb}$ & 2 & 10 & & $83 \%$ & & $90 \%$ \\
\hline \multicolumn{7}{|c|}{ Sputum eosinophilia } \\
\hline$<4 \%$ & 13 & 6 & $68 \%$ & & $54 \%$ & \\
\hline$\geqslant 4 \%$ & 4 & 7 & & $64 \%$ & & $76 \%$ \\
\hline \multicolumn{7}{|c|}{$\begin{array}{l}\text { Increased NO and/or } \\
\text { eosinophil count }\end{array}$} \\
\hline No & 15 & 4 & $79 \%$ & & $76 \%$ & \\
\hline Yes & 5 & 13 & & $72 \%$ & & $75 \%$ \\
\hline
\end{tabular}

cence. The technique used is that recommended by the European Respiratory Society Task Force. ${ }^{5}$ An increased concentration of exhaled NO was defined as $\geqslant 10 \mathrm{ppb}$ on the basis of our own experience and other work. ${ }^{5}$

\section{Sputum induction}

Sputum induction was performed following assessment of reversibility to salbutamol using a modification of the method described by Pin et al. ${ }^{1}$ The sample was collected in a sterile container and transferred to the laboratory on ice as quickly as possible, and in all cases in less than two hours.

All samples were processed without the laboratory staff being aware of the clinical information relating to the individual subject, and the procedure followed was similar to that described by Popov et al. ${ }^{6}$ Sputum eosinophilia was defined as $\geqslant 4 \%$ eosinophils, consistent with previous work. ${ }^{7}$

Histamine inhalational challenge

Bronchial hyperresponsiveness to histamine was established using doubling doses of inhaled histamine from 0.0625 to $16 \mathrm{mg} / \mathrm{ml}^{8}{ }^{8}$ The test was performed within a few days of completion of the steroid trial.

\section{STATISTICAL ANALYSIS}

Descriptive statistics were summarised as mean, median, and standard deviation. A clinically significant improvement in best forced expiratory volume in one second $\left(\mathrm{FEV}_{1}\right)$ following the steroid trial and bronchodilator was defined as $a \geqslant 15 \%$ increase as a percentage of the baseline value. Correlations between
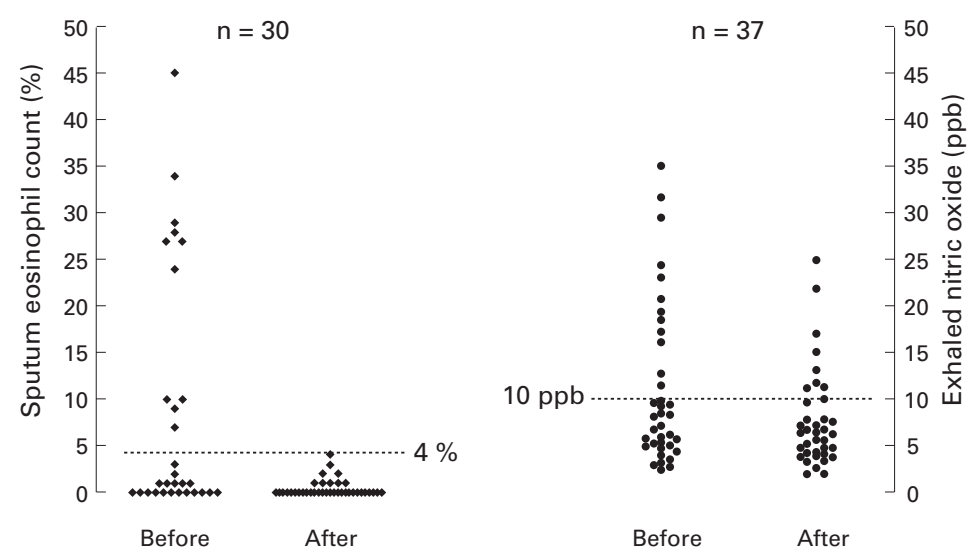

Figure 1 Induced sputum eosinophil count and exhaled nitric oxide levels before and after the steroid trial. exhaled NO concentrations, sputum eosinophilia, and increase in $\mathrm{FEV}_{1}$ were assessed using Spearman rank correlation coefficients. Ranked correlations were also assessed between NO, eosinophilia, and bronchial hyperresponsiveness $\left(\log \mathrm{PC}_{20}\right)$. The predictive values for each test were determined using $2 \times 2$ contingency tables, permitting calculation of positive and negative predictive values, and sensitivity and specificity.

\section{Results}

Thirty seven asthmatic subjects (19 women) of mean (SD) age 48.6 (12.2) years, asthma duration 25.9 (17.3) years, and baseline $\mathrm{FEV}_{1}$ $76.3(21.9) \%$ predicted were recruited into the study. All but one was taking inhaled steroids with a median dose equivalent to $800 \mu \mathrm{g}$ beclomethasone (interquartile range 400$1000 \mu \mathrm{g})$.

Despite being on inhaled steroids, 12 of the patients $(32 \%)$ had an increased level of NO. Of the 30 patients producing sufficient sputum for analysis, $11(37 \%)$ had sputum eosinophilia. There was no significant correlation between the inhaled steroid dose and baseline exhaled NO levels $\left(r_{\mathrm{s}}=-0.21, \mathrm{p}=0.22\right)$ or between the inhaled steroid dose and baseline sputum eosinophil count $\left(r_{\mathrm{s}}=0.17, \mathrm{p}=0.36\right)$. After treatment with oral steroids there was a statistically significant correlation between baseline NO levels and percentage change in $\mathrm{FEV}_{1}\left(r_{\mathrm{s}}=0.47, \mathrm{p}=0.003\right)$, but the scatter was such that the change in $\mathrm{FEV}_{1}$ could not be predicted by baseline NO alone. No correlation was seen between baseline sputum eosinophil count and improvement in $\mathrm{FEV}_{1}\left(r_{\mathrm{s}}=0.19, \mathrm{p}=\right.$ $0.30)$.

Of those patients with an increased NO level at baseline, $83 \%$ developed an increase in $\mathrm{FEV}_{1}$ of $\geqslant 15 \%$ after oral steroids (positive predictive value of $83 \%$, table 1). For sputum eosinophilia the positive predictive value was $64 \%$ but the sensitivity of these tests was low at $59 \%$ and $54 \%$, respectively. We combined the tests, dividing the group on the basis of having one or other marker increased or neither marker increased. The resulting positive predictive value was $72 \%$ with an improved sensitivity of $76 \%$. The negative predictive value was $79 \%$ (specificity $75 \%$ ) such that, of those subjects with a normal exhaled NO level and sputum eosinophilia of $<4 \%, 79 \%$ had an improvement in $\mathrm{FEV}_{1}$ of $<15 \%$.

Following a trial of steroid therapy sputum eosinophilia essentially resolved but, although exhaled NO levels fell, they did not return to a normal level in all subjects (fig 1). Finally, ranked correlations were performed between $\mathrm{NO}$ and $\log \mathrm{PC}_{20}$ and between eosinophil count and $\log \mathrm{PC}_{20}$ but neither reached statistical significance ( $p=0.11$ and $p=0.33$, respectively).

\section{Discussion}

We have shown that, in a group of chronic asthmatic subjects who had not experienced a recent exacerbation, a significant proportion had raised levels of exhaled NO and sputum eosinophilia. Our results show that exhaled NO levels and sputum eosinophilia can be used to 
predict a response in lung function following an oral steroid trial, with a combination of these two markers producing significantly improved sensitivity and specificity. Of potential clinical applicability is the negative predictive value of this combination, with $79 \%$ of those without increased NO levels or significant sputum eosinophilia having an improvement in $\mathrm{FEV}_{1}$ of $<15 \%$.

The markers used for this study are acceptable for patients and reproducible, although both have limitations and neither alone produced a clinically acceptable positive predictive value. Induced sputum is a useful technique for studying the effects of asthma treatment on airway eosinophilic inflammation, but not all patients are able to produce a sample sufficient for analysis. Although airway inflammation is present in newly diagnosed and mild asthmatics, exacerbations may not be associated with sputum eosinophilia ${ }^{7}$ and there is evidence for the role of other inflammatory cells in asthmatic airway inflammation, particularly in patients with irreversible airflow obstruction. ${ }^{9}$ Asthmatic airway inflammation may therefore be a heterogeneous process of which sputum eosinophilia is only one part, and it may be that sputum eosinophilia and exhaled NO levels reflect different components of the inflammatory process. The improvement in sensitivity and specificity within this study using the combination of the two markers would be in keeping with this.

Nitric oxide is a non-specific marker of airway inflammation, being increased in conditions other than asthma-for example, bronchiectasis and cystic fibrosis. Patients with asthma have higher levels of NO than normal individuals, ${ }^{3}$ which relate to airway inflammation, and treatment with steroids produces a reduction in these levels. ${ }^{4}$ However, the range of NO levels in asthmatic patients is large with some having normal values and others having increased levels despite treatment with inhaled steroids. Whilst the latter may suggest insufficient treatment, the NO measurements follow- ing steroid treatment in this study are interesting because they show that, although levels fall, they do not return to normal in all patients despite oral steroid treatment. A dose dependent effect seems unlikely, given that all patients received a two week course of oral steroid, and the mechanism for the persistent increase in $\mathrm{NO}$ is unclear.

Assuming that uncontrolled inflammation results in airway remodelling, ${ }^{10}$ treatment should be aimed at controlling that process and in maximising lung function. The two markers employed in this study, although not ideal, provide some predictive value of improvement in lung function in a broad spectrum of asthmatic subjects, and suggest the potential use of such markers in predicting best lung function and hence identifying those patients in whom an increase in dose of inhaled corticosteroid may be beneficial. Addition of further markers might increase the predictive values but reduce clinical applicability.

Funding: National Asthma Campaign.

1 Pin I, Gibson PG, Kolendowicz R, et al. Use of induced sputum cell counts to investigate airway inflammation in asthma. Thorax 1992;47:25-9.

2 Pavord ID, Brightling CE, Woltmann G, et al. Noneosinophilic corticosteroid unresponsive asthma. Lancet 1999;353:2213-4.

3 Kharitonov SA, Yates D, Robbins RA, et al. Increased nitric oxide in exhaled air of asthmatic patients. Lancet 1994;343: $133-5$.

4 Kharitonov SA, Yates DH, Barnes PJ. Inhaled glucocorticoids decrease nitric oxide in exhaled air of asthmatic patients. Am f Respir Crit Care Med 1996;153:454-7.

5 Kharitonov S, Alving K, Barnes PJ. Exhaled and nasal nitric oxide measurements: recommendations. Eur Respir f 1997; 10:1683-93.

6 Popov T, Gottschalk R, Kolendowicz R, et al. The evaluation of a cell dispersion method of sputum examination. Clin Exp Allergy 1994;24:778-83.

7 Turner MO, Hussack P, Sears MR, et al. Exacerbations of asthma without sputum eosinophilia. Thorax 1995;50: 1057-61.

8 Hargreave FE, Ryan G, Thomson NC, et al. Bronchial responsiveness to histamine or methacholine in asthma: measurement and clinical significance. I Allergy Clin Immunol 1981;68:347-55.

9 Vignola AM, Chanez P, Campbell AM, et al. Airway inflammation in mild intermittent and in persistent asthma. $A m \mathcal{F}$ mespir Crit Care Med 1998;157:403-9.

10 Fabbri LM, Caramori G, Beghe B, et al. Physiologic consequences of long-term inflammation. Am $\mathcal{F}$ Respir Crit Care Med 1998;157:S195-8. 